\title{
As condições de trabalho docente e o pós-estado de bem-estar social
}

\author{
Regivane dos Santos Brito* \\ Jany Rodrigues Prado** \\ Claudio Pinto Nunes***
}

\section{Resumo}

O propósito deste artigo é discutir os entrelaçamentos entre o pós-estado de bem-estar social e as condições de trabalho docente. Para tanto, compreende as condições de trabalho dos profissionais em educação a partir dos fatores que envolvem sua remuneração, sua jornada de trabalho e sua forma de contratação na sociedade capitalista. O texto evidencia que, no Brasil, tem-se acompanhado um movimento de dilatação das atividades do professor, a partir da desregulação e da redefinição das suas atividades laborais, que, consequentemente, tem contribuído para a intensificação e precarização do trabalho docente. Diante desse cenário, faz-se urgente repensar algumas questões que envolvem a docência, como os tempos pedagógicos e formativos, os espaços e os recursos necessários para realizar a ação pedagógica qualificada, valorização da atividade docente, jornada única, formação continuada, melhoria da remuneração e garantia de condições dignas de trabalho.

Palavras-chave: Condições de trabalho docente. Pós-estado de bem-estar social. Saúde do professor.

\footnotetext{
* Mestranda em Educação pela Universidade Estadual do Sudoeste da Bahia (UESB). Graduada em Pedagogia pela Universidade Estadual do Sudoeste da Bahia (UESB). Membro do Grupo de Pesquisa Didática, Formação e Trabalho Docente (Difort/CNPq). E-mail: regivanne_brito@ live.com

** Mestranda em Educação pela Universidade Estadual do Sudoeste da Bahia (UESB). Graduada em Pedagogia pela Universidade do Estado da Bahia (UNEB). Professora Substituta do Departamento de Educação da Universidade do Estado da Bahia - UNEB/Campus XII. Coordenadora Pedagógica da rede municipal de Guanambi - BA.E-mail: janyrprado@ yahoo.com.br

*** Doutor em Educação, pela Universidade Federal do Rio Grande do Norte (UFRN). Pós-Doutor Educação, pela Universidade Federal de Minas Gerais (UFMG). Professor Titular da Universidade Estadual do Sudoeste da Bahia (UESB). Docente do Programa de Pós-Graduação em Educação da UESB. E-mail: claudionunesba@hotmail.com
} 


\section{Working conditions of teachers and post-state of social welfare}

\section{Las condiciones de trabajo docente y el post-estado de bienestar social}

\section{Abstract}

The purpose of this article is to discuss the interweaving between post-state of social welfare and working conditions of teachers. To this end, it understands the working conditions of education professionals based on the factors that involve pay, working hours and the form of employment in capitalist society. The text shows that, in Brazil, there was a movement of expansion of the teacher's activities, due to the deregulation and redefinition of his work activities, which, consequently, contributed to the intensification and precarization of teaching work. Given this scenario, it is urgent to rethink some issues that involve teaching, such as pedagogical and formative schedules, spaces and resources necessary to carry out qualified pedagogical actions, evaluation of teaching activity, single journey, continuous training, improvement of remuneration and guarantee of conditions of Decent work.

Keywords: Working conditions of teachers. Post-state of social welfare. Teacher health.

\section{Resumen}

El propósito de este artículo es discutir los entrelazamientos entre el post-estado de bienestar social y las condiciones de trabajo docente. Para ello, comprende las condiciones de trabajo de los profesionales en educación desde los factores que involucran su remuneración, su jornada de trabajo y su forma de contratación en la sociedad capitalista. El texto evidencia que, en Brasil, se ha acompañado un movimiento de dilatación de las actividades del profesor, desde la desregulación y de la redefinición de sus actividades laborales, que, consecuentemente, ha contribuido a la intensificación y precarización del trabajo docente. Ante este escenario, se hace urgente repensar algunas cuestiones que involucran a la docencia, como los tiempos pedagógicos y formativos, los espacios y los recursos necesarios para realizar la acción pedagógica cualificada, valorización de la actividad docente, jornada única, formación continuada, mejora de la remuneración Y garantía de condiciones dignas de trabajo.

Palabras clave: Condiciones de trabajo docente. Post-estado de bienestar social. Salud del profesor. 
Introduzindo a temática: o pós-estado de bem-estar social e a desprofissionalização docente

Pensar as condições de trabalho do profissional em educação implica pensar as condições de emprego deste profissional, sua forma de contratação, remuneração, carreira e estabilidade. Implica também compreender que essas condições são determinadas pela organização do trabalho no capitalismo.

Por tais razões, a análise sobre as condições de trabalho docente deve se situar no tempo e no espaço, ou seja, no contexto histórico-social e econômico que as engendram. (OLIVEIRA; ASSUNÇÃO, 2010).

A compreensão acerca das mudanças que ocorreram no âmbito do Estado é de suma importância para desvelarmos as condições de trabalho que envolvem o profissional que exerce a docência. Num cenário marcado pela globalização, a redefinição do papel do Estado apresenta novas formas de organização na estrutura e na forma de governança das instituições, que interfere diretamente na vida dos profissionais. Ball (2004) sinaliza que essas mudanças estão relacionadas a "um novo conjunto de relações sociais de governança", em que há novas distribuições de responsabilidades e funções.

Uma das grandes mudanças refere-se à passagem do Estado provedor para o Estado regulador, que fiscaliza, que audita, que avalia e que, a cada dia que passa, se ajusta aos ditames neoliberais. Essa mudança não significa que o Estado será menos ativo ou intruso, significa que ele agirá de modo diferente. (BALL, 2010).

Nessa lógica, o Estado deixa "de ser o responsável direto pelo desenvolvimento econômico e social pela via da produção de bens e serviços, para fortalecer-se na função de promotor e regulador desse desenvolvimento". (BRASIL, 1995, p. 12). Esse processo acontece de diversas formas, como por exemplo, através da terceirização, privatização de empresas estatais e da publicização, que consiste na "descentralização para o setor público não-estatal da execução de serviços que não envolvem o exercício do poder de Estado, [...] mas que devem ser subsidiados pelo Estado, como é o caso dos serviços de educação, saúde, cultura e pesquisa científica" (BRASIL, 1995, p. 12-13). Assim, o Estado passa a transferir recursos públicos para o setor privado executar tais serviços, e, atua apenas na regulação e avaliação desses processos. Essa redefinição do Estado, segundo Ball (2004) acarreta duas mudanças políticas:

\begin{abstract}
Primeiro, uma vez livre da responsabilidade exclusiva pela prestação direta de serviços, o Estado pode considerar vários prestadores potenciais de serviços - públicos, voluntários e privados. Isso introduz contestabilidade e concorrência entre prestadores potenciais na base de "o melhor serviço" e/ou valor pelo dinheiro, e envolve o uso de modelos comerciais de licitação e contratação. Segundo, isso também permite considerar modelos alternativos de financiamento, e a participação de financiadores privados para desenvolver a infra-estrutura do setor público. Esses arranjos envolvem fornecedores do setor privado na construção e na gestão de escolas, hospitais, prédios universitários etc. na base de um contrato de arrendamento de retorno (lease-back) e de gestão. $\mathrm{Na}$ maioria desses casos, a mão-de-obra direta do setor público é substituída pela do contratante e alguns comentaristas temem que, num dado momento, essa contratação de mão-de-obra, além das refeições, da limpeza, da manutenção, da segurança etc. ("hard services"), possa se estender a tarefas centrais como ensino, pesquisa etc. ("soft services"). (BALL, 2004, p.1109-1110).
\end{abstract}

Percebe-se nessa conjuntura, que os serviços sociais se tornaram "uma área em expansão na qual lucros consideráveis podem ser obtidos" (BALL, 2004, p.1107). A educação, inserida nesse contexto, segundo Ball (2004, p.1108) passa a ser "uma oportunidade de negócios" compreendida como um dos meios através do qual o Estado pode garantir as bases do sistema de acumulação, controle social, competitividade e ajustamento estrutural.

A educação passa a ser um investimento com vistas ao desenvolvimento da capacidade produtiva do homem, adaptável às demandas do capital, sob a égide de um discurso de combate à exclusão social, erradicação da pobreza e a construção de uma sociedade mais demo- 
crática. Desse modo, o papel da educação é contribuir para o crescimento econômico, por meio de um ensino voltado para formação de sujeitos com competências, habilidades e capacidades necessárias para atuar no mercado de trabalho. O Estado como bom estrategista, dentro dessa lógica capitalista, compreende a educação como forma de desenvolver o capital humano.

Nessa direção, as reformas educacionais no Brasil assentam-se nos princípios de maior eficiência e produtividade visando ao crescimento econômico. Tais reformas passaram a sofrer influência dos organismos internacionais, como Organização dos Estados Americanos (OEA), Banco Interamericano de Desenvolvimento (BID), Banco Mundial (BM), Comunidade Europeia (CE), Organização para Cooperação e Desenvolvimento Econômico (OCDE), Programa das Nações Unidas para o Desenvolvimento (PNUD), Programa das Reformas Educacionais da América Latina e Caribe (PREAL), dentre outras.

Essas organizações passaram a exercer forte influência na definição das diretrizes, nos países em desenvolvimento, como no caso do Brasil, apontando condições essenciais para melhores resultados na educação, que envolvem maior flexibilidade das leis e normas de contratação docente, incentivos salariais seletivos, recompensas não monetárias, ampliação do tempo exigido para aposentadoria, maior ênfase na formação por habilidades que nos conteúdos informativos e a premiação das escolas e professores pelos bons resultados nas avaliações externas. Ball (2010) ratifica essa ideia, quando afirma que a preocupação com as questões educacionais cede lugar às demandas do mercado, compreendendo a educação enquanto um bem de consumo, e os docentes transformados em mercadoria ou obrigados a assumir essa "forma", mercantilizando sua força de trabalho e seu conhecimento.

Consequentemente, essas ações impactam a vida do professor que se encontra em um cenário político de expropriação dos seus direitos, visto que há um crescimento do número de professores contratados temporariamente, professores efetivos com duplas jornadas de trabalho, manutenção de baixos salários, precarização da formação inicial docente e desarticulação do coletivo dessa categoria, que se encontra em um processo de mercantilização vivido e ressaltado pela meritocracia. "Essa mudança é tão profunda, que no regime do "pós-Estado de Bem-estar", o profissionalismo como prática cultural não tem lugar, não tem futuro". (BALL, 2005, p. 541).

Nunes e Oliveira (2017) destacam que, quando não há profissionalização e sim proletarização, o que ocorre é a degradação do estatuto, dos rendimentos e do poder/autonomia do professor. Além da estandartização de tarefas, são recorrentes a dicotomia entre a concepção e execução das atividades docentes, a redução dos custos necessários à aquisição da força de trabalho e a intensificação das exigências em relação às atividades dos professores. Ball (2011, p.28) afirma que "o profissionalismo é substituído por responsabilização e o coleguismo por competição e comparação interpessoal de performances".

\section{Problematizando: a desprofissionalização no contexto da performatividade e do gerencialismo}

Ball (2005) advoga que a erradicação do profissionalismo é decorrente dos efeitos combinados das tecnologias da performatividade e do gerencialismo:

A performatividade é uma tecnologia, uma cultura e um método de regulamentação que emprega julgamentos, comparações e demonstrações como meio de controle, atrito e mudança. Os desempenhos de sujeitos individuais ou de organizações servem de parâmetros de produtividade ou de resultado, ou servem ainda como demonstrações de "qualidade" ou "momentos" de promoção ou inspeção. Eles significam ou representam merecimento, qualidade ou valor de um indivíduo ou organização dentro de uma área de julgamento, tornando os "silêncios audíveis". (BALL, 2005, p. 543). [...]

O gerencialismo desempenha o importante papel de destruir os sistemas ético-profissionais que prevaleciam nas escolas, provocando sua substituição por sistemas empresariais competitivos. O trabalho do gerente envolve incutir uma atitude e uma cultura nas quais os trabaIhadores se sentem responsáveis e, ao mesmo tempo, de certa forma pessoalmente investidos 
da responsabilidade pelo bem-estar da organização. (BALL, 2005, p. 544-545).

Tais tecnologias importadas do mundo empresarial trazem consigo a responsabilização do professor pelo sucesso e/ou insucesso de seus alunos e mudam o significado do que é ser professor. De acordo com Ball (2004), as mudanças nas instituições do setor público caminham,

[...] rumo a um quadro de novas possibilidades éticas, de novos papéis e relações de trabalho - uma nova economia moral. A instauração de uma nova cultura de performatividade competitiva que envolve uma combinação de descentralização, alvos e incentivos para produzir novos perfis institucionais. (BALL, 2004, p. 1.107).

O novo perfil do professor tem como base a competência e a eficiência para apresentar bons resultados nas avaliações externas. Diante disso, o professor passa a operar dentro de uma imensidão de dados, indicadores, comparações e competições, em que a estabilidade é passageira e as motivações pessoais são substituídas pelas necessidades profissionais. "O ato de ensinar e a subjetividade do professor ambos sofrem profundas mudanças com o novo panopticismo da gestão (de qualidade e excelência) e as novas formas de controle empresarial (por meio do marketing e da concorrência)". (BALL, 2004, p. 1.118).

Deste modo, a performatividade está ligada à competência, à qualidade, à excelência, à eficiência, à avaliação, aos melhores resultados nos rankings, entre outros. Tudo isso gera a competitividade, a comparação, os julgamentos e exposições. Pode-se dizer que, no contexto das reformas educacionais que está diretamente ligado à globalização e ao crescimento econômico, os valores foram deixados de lado e a performatividade se tornou mais importante. Os sujeitos e as organizações precisam apresentar bons resultados nas avaliações para serem reconhecidos e recompensados.

Assim, cada sujeito ou organização representa um valor dentro do que Ball (2010) chama de "campo de julgamento". No caso dos professores, seu desempenho tem sido julgado de acordo com os resultados obtidos por seus alunos nas avaliações realizadas em larga escala, que promovem a competição e a comparação nos rankings a nível nacional e mundial.

\begin{abstract}
Observa-se, hoje, grande pressão para que os professores apresentem melhor desempenho, principalmente no sentido de os estudantes obterem melhores resultados nos exames nacionais e internacionais. As críticas ressaltam, sobretudo, os professores como mal formados e pouco imbuídos de sua responsabilidade pelo desempenho dos estudantes. (SCHEIBE, 2010, p. 985).
\end{abstract}

Percebe-se então, a responsabilização do professor pelo bom desempenho dos seus alunos, e, as avaliações externas sendo utilizadas como instrumento de controle e monitoramento do trabalho docente, como sinaliza Melo (2015, p. 110) (grifo da autora).

[...] essas avaliações, padronizadas em larga escala, tornam-se verdadeiros instrumentos de regulação e controle docente por parte do Estado, pois a medição do desempenho estudantil insurge como "prestação de contas" à sociedade e como avaliação do desempenho dos docentes.

Nesse cenário, marcado pela responsabilização docente, as reformas anunciam a necessidade de uma nova educação, um novo professor e novas práticas pedagógicas, ancoradas no discurso de que esse profissional não está preparado para exercer suas atividades laborais e de que suas práticas são ultrapassadas e pouco eficazes. Ball (2004) salienta que,

Os discursos da responsabilidade (accountability), da melhoria, da qualidade e da eficiência [...] tornam as práticas existentes frágeis e indefensáveis - a mudança torna-se inevitável e irresistível, mais particularmente quando os incentivos estão vinculados às medidas de desempenho. (BALL, 2004, p. 1116).

Ao professor cabem novas responsabilidades frente às novas demandas educacionais. No Brasil, Assunção e Oliveira (2009) reiteram que, a partir da Constituição Federal de 1988, e da Lei de Diretrizes e Bases da Educação 
Nacional - LDBEN no 9.394/96 - tem-se acompanhado um movimento de dilatação das atividades do professor e, consequentemente, de precarização das condições de trabalho docente. A LDBEN no 9.394/96, em seus artigos 12,13 e 14, afirma que o trabalho docente não se limita às atividades em sala de aula, mas envolve atividades com a comunidade escolar, a gestão da escola, o planejamento do projeto político-pedagógico, a participação nos órgãos colegiados, dentre outras atividades. Esta ampliação do que abarca ou do que compõe o conceito de trabalho docente termina por dilatar as obrigações ou tarefas do dia a dia do professor. Tal dilatação, a partir da desregulação e da redefinição das atividades laborais do professor, tem contribuído para a precarização das condições de trabalho docente.

Diante da ampliação das demandas trazidas pelas políticas mais recentes, o professor é chamado a desenvolver novas competências necessárias para o pleno exercício de suas atividades docentes. O sistema espera preparo, formação e estímulo do sujeito docente para exercer o pleno domínio da sala de aula e para responder às exigências que chegam à escola no grau de diversidade que apresentam e na urgência que reclamam. (ASSUNÇÃO; OLIVEIRA, 2009, p. 355).

O professor precisa pensar e criar novas estratégias de ensino e aprendizagem; novas formas de avaliar frente às exigências das avaliações sistêmicas; adequar-se aos tempos pedagógicos da escola e criar outros tempos formativos, a fim de garantir diálogo com seus pares; planejar e (re)planejar situações didáticas e participar de processos de formação continuada; oportunizar tempo para atendimentos individuais dos alunos e seus responsáveis e tempos para pensar criticamente sua ação pedagógica.

Essas novas atribuições, marcadas pelo alargamento das atividades docentes, surgem dentro de uma carga horária que não se dilata, não se amplia. Assiste-se, então, a uma ampliação da jornada de trabalho e um processo de responsabilização docente aliado ao lado perverso da autointensificação do trabalho, pois muitas das questões atribuídas ao professor não podem ser resolvidas por ele, já que ele não dispõe de recursos e tampouco condições para fazer esses enfrentamentos. Tem-se, desta forma, um profissional imerso na competitividade, na produtividade, na eficiência e no treinamento não intelectualizado, baseado na formação por competência, conforme destaca Ball (2005).

O professor, imerso no processo de responsabilização, sente-se inseguro, não sabe se está fazendo a coisa certa, se está fazendo o suficiente ou se não poderia fazer meIhor, segue assim, numa busca incessante pela excelência e pela perfeição. (BALL, 2004). Nessa busca constante, as relações estabelecidas dentro das instituições pressupõem a disputa, comparações, julgamentos e a concorrência entre os pares, gerando conflitos e transformando a educação em um campo em que se estabelecem relações de poder, ou seja, se transformou em "uma arena de competição de soma zero (em que ninguém ganha sem que outro perca), cheia de atores interessados em si mesmos e em busca de oportunidades". (LARABEE, 1997 apud BALL, 2004, p.1.120).

Dentro das instituições como as escolas, a competição entre os profissionais gera uma série de sentimentos que afetam as relações e o bem-estar coletivo, [...] "sentimentos individuais de orgulho, de culpa, de vergonha e de inveja - que tem uma dimensão emocional (status), assim como (a aparência de) racionalidade e objetividade". (BALL, 2010, p.40). Esses sentimentos têm se tornado cada vez mais comum, como algo natural do ser humano, e os profissionais dentro dessa lógica do mercado, na maioria das vezes, não percebem que estão agindo para atender aos interesses do capital. A ideia da necessidade de ser um profissional competente e eficiente faz com que as disputas e o individualismo nos locais de trabalho sejam naturalizados.

Outra faceta que envolve as condições de trabalho docente está relacionada ao adoecimento, à frustração do professor e sua insatisfação com o trabalho. Diante desse contexto, marcado pela performatividade, o professor passa a trabalhar em um ritmo acelerado para dar conta das demandas que surgem o tempo todo, e, isso pode trazer graves consequências à saúde desse profissional. Assunção e Oliveira (2009, p. 361) explicam que 
Executar outras tarefas durante o curso da ação principal, atender ao aluno individualmente e controlar a turma coletivamente e preencher múltiplos instrumentos e formulários de controle são dimensões da intensificação do trabalho que implicam regular na urgência. Situações de sobreposição de tarefas podem explicar o cansaço físico, vocal e mental do docente. De modo geral, para responder às múltiplas demandas, os trabalhadores elaboram estratégias operatórias que resultam em hipersolicitação do corpo.

Os distúrbios vocais são um dos problemas mais comuns que afetam a saúde dos docentes e acontecem em decorrência do uso excessivo da voz na sala de aula, principalmente, nas turmas superlotadas. Em geral, a superlotação é mais comum nas escolas públicas, por várias razões, dentre elas, a falta de estrutura física para atender o quantitativo de alunos.

Para desempenhar suas atividades, os professores, na maioria das vezes, são obrigados a aumentar o tom de sua voz para sobrepor aos ruídos da sala de aula e de outros ambientes externos, consequentemente, isso pode provocar distúrbios vocais e outros transtornos. No estudo realizado por Assunção e Oliveira (2009) as autoras destacam que

Os professores são considerados os profissionais com mais alto risco para o desenvolvimento de distúrbios vocais e apresentam maior prevalência de queixas vocais específicas quando comparados com os outros profissionais. [...] É comum o esforço do professor em sobrepor a intensidade de sua voz ao ruído ambiental. (ASSUNÇÃO; OLIVEIRA, 2009, p. 361-362).

O uso excessivo da voz também está concatenado à jornada de trabalho do professor, geralmente, os professores assumem uma extensa carga horária de atividades em sala de aula, em uma ou mais instituições de ensino públicas ou privadas. "Os professores são, comumente, responsáveis por várias turmas em dois turnos de funcionamento das escolas: manhã/tarde, manhã/ noite ou tarde/noite, sobretudo quando se trata das séries finais do ensino fundamental e das séries do ensino médio" (SAMPAIO; MARIN, 2004, p. 1216). Essa jornada de traba-
Iho além de agravar os distúrbios vocais, resulta em cansaço físico e mental. "Cronicamente cansados, o padrão e a qualidade do sono e a disposição para o desfrute do lazer e a prática de hábitos saudáveis encontram-se fragilizados". (ASSUNÇÃO; OLIVEIRA, 2009, p. 362).

Nesse cenário de reformas em que os docentes passam a assumir várias funções e responsabilidades, muitas vezes eles não dão conta de realizar todas as tarefas na escola, e, acabam realizando essas atividades em casa, durante a noite ou nos finais de semana, nos momentos que deveriam ser destinados/reservados para o descanso e o lazer. Daí a necessidade de os sistemas de ensino garantirem aos profissionais do magistério o direito a um tempo específico para a realização de atividades pedagógicas fora do ambiente da sala de aula. Esse tempo deve ser destinado ao planejamento e organização de outras atividades. De acordo com Sampaio e Marin (2004, p. 1213),

[...] estudos mostram que, sobretudo na última década, diversas instituições públicas e privadas implantaram este tipo de apoio: horas para o desenvolvimento das atividades de preparo de aulas, de correção de trabalhos de alunos, apoio aos alunos nas atividades extracurriculares e de formação em serviço para os próprios professores. Essas atividades ligadas ao currículo das escolas, feitas fora da sala de aula e da presença de alunos, recebem nomes e organizações diversas nas redes de ensino: Horário de Trabalho Pedagógico Coletivo (HTPC), horas-atividade individuais ou coletivas, realizadas nas escolas ou em ambientes de escolha dos professores.

Em longo prazo, a falta de descanso, de lazer e de hábitos saudáveis como a prática de atividade física, podem comprometer seriamente a saúde dos docentes. Têm-se observado um número crescente de professores que relatam problemas sérios de saúde que interferem no desenvolvimento de suas atividades na sala de aula. Em alguns casos, esses profissionais conseguem transferência para outros setores, principalmente, os administrativos. Geralmente, os docentes costumam apresentar quadros de depressão, ansiedade, stress, nervosismo, além de sintomas físicos como dores e cansaço. Esses sintomas surgem em decorrência de diversos fatores. No ambiente 
escolar, Kagan (1989 apud ASSUNÇÃO; OLIVEIRA, 2009, p. 365) destaca cinco categorias que agrupam fatores potencialmente estressantes:

\begin{abstract}
a) falta de apoio administrativo (percebem que o diretor tem pouca consideração pelos problemas da sala de aula); b) a relação com os alunos (sentimento de incapacidade para motivar ou controlar os alunos); c) a relação com os colegas (percebem animosidade na relação com os colegas e distribuição desigual das tarefas entre os pares); d) excesso de trabalho (percebem excesso de expectativa da gestão quanto ao volume de tarefas a serem realizadas por eles); e) insegurança financeira (salários inadequados e discrepantes em face do grau de responsabilidade da sua missão).
\end{abstract}

No Brasil, a remuneração dos profissionais que exercem a docência se caracteriza como um processo de precarização e desvalorização da profissão. "Uma das questões bem visíveis da precarização do trabalho do professor refere-se ao salário recebido pelo tempo de dedicação às suas funções, sobretudo quando se focaliza a imensa maioria, ou seja, os que atuam nas diversas escolas da rede pública". (SAMPAIO; MARIN, 2004, p. 1210).

Além disso, existe uma variação na remuneração dos docentes conforme os sistemas de ensino e as regiões do país, como apontam Duarte e Oliveira (2014, p. 72).

\footnotetext{
Os profissionais da educação básica no Brasil são contratados e remunerados pelos estados e municípios, o que resulta em grande desigualdade salarial e de condições de trabalho entre professores das diferentes regiões do país, pois cada estado e município tem liberdade para criar e definir suas próprias carreiras e planos salariais, a despeito da legislação federal definir diretrizes de carreira docente em nível nacional (Resolução n. 02/2009) e um Piso Salarial Profissional Nacional (Lei n. 11.738/2008).
}

Essa variação salarial acontece também de acordo com o vínculo empregatício (efetivo ou temporário), neste caso, os professores executam as mesmas atividades, mas os salários são diferenciados. Observa-se um crescente nú- mero de professores temporários nas instituições como estratégia dos governantes para diminuir os custos, haja vista, que esses profissionais não têm estabilidade na carreira, não têm direito às gratificações, décimo terceiro, férias, além de outros direitos que são garantidos aos professores efetivos.

Tal situação tem-se agravado com as mudanças ocorridas no atual cenário político brasileiro, que têm caminhado na direção da desvalorização e precarização do trabalho docente. Algumas alterações já estão presentes nos documentos legais e outras em andamento, como por exemplo, a Lei no 13.429, de 31 de março de 2017', conhecida como a Lei da Terceirização, a Emenda Constitucional no 95 , de 15 de dezembro de 2016 que institui o novo regime fiscal, o Projeto de Lei no 6.787/2016² da Reforma Trabalhista e a Proposta de Emenda Constitucional - PEC n 287/2016³, conhecida como Reforma da Previdência. Todos esses documentos afetam diretamente as áreas sociais, inclusive a educação, e compromete o futuro do país.

Com essas mudanças o quadro de professores temporários nas escolas pode aumentar ainda mais, e a realização de concursos públicos pode se tornar cada vez mais escassa. Os professores dentro desse contexto de expropriação dos seus direitos e desvalorização da sua carreira sentem-se angustiados, frustrados e insatisfeitos com a profissão.

\section{Tecendo algumas considerações}

As reflexões pontuadas acerca das condições de trabalho docente delineiam um quadro preocupante. As reformas educacionais no contexto de redefinição do papel do Estado apresentam novas formas de organização na estrutura e na gestão das instituições, que traz implicações para a profissão docente.

Num mundo globalizado e marcado pelo capitalismo em expansão, a educação se transformou em uma mercadoria que pode garantir as bases do sistema de acumulação, controle social, competitividade e ajustamento estrutural, por meio de um ensino voltado para o desen- 
volvimento da capacidade produtiva do homem, adaptável às demandas do capital.

Esse atual paradigma educacional impacta a vida dos professores na medida em que eles passam a assumir novas funções e responsabilidades. Ball (2005) afirma que duas tecnologias importadas do mundo empresarial têm aproximado a educação da lógica do mercado - a performatividade e o gerencialismo. Tais tecnologias empregadas na educação apontam para a necessidade de um novo professor e novas práticas pedagógicas.

O novo professor deve ser um profissional competente e eficiente que apresente bom desempenho nas atividades. Esse desempenho tem sido avaliado com base nos resultados obtidos por seus alunos, nas avaliações realizadas em larga escala. Deste modo, o professor é responsável pelo sucesso e/ou insucesso dos alunos.

No Brasil, tem-se acompanhado um movimento de dilatação das atividades do professor a partir da desregulação e da redefinição das suas atividades laborais, consequentemente, isso tem contribuído para a precarização das condições de trabalho docente.

As novas atribuições e a urgência em atender as demandas provocam a intensificação do trabalho e pode trazer graves consequências à saúde do professor. Dentre os problemas mais comuns estão os distúrbios vocais, em decorrência do uso excessivo da voz na sala de aula.

A extensa carga horária assumida por muitos profissionais além de agravar os distúrbios vocais, resulta em cansaço físico e mental. Geralmente, os docentes costumam apresentar quadros de depressão, ansiedade, estresse, nervosismo, além de sintomas físicos como dores e cansaço. Esses sintomas surgem em decorrência de diversos fatores, e em alguns casos, é necessário o afastamento dos professores da sala de aula.

No Brasil, outro fator que impacta as condições de trabaIho docente está relacionado à remuneração. Além dos baixos salários da categoria, existe também uma varia- ção salarial conforme os sistemas de ensino, as regiões do país e o vínculo empregatício (efetivo ou temporário). Esse quadro se caracteriza como um processo de precarização e desvalorização da profissão.

$\mathrm{Na}$ atual conjuntura, os professores se encontram imersos em um cenário político de expropriação dos seus direitos e desvalorização da sua carreira que provoca sentimentos de angústia, frustração e insatisfação com a profissão.

Diante desse cenário, faz-se urgente repensar algumas questões que envolvem a docência, como os tempos pedagógicos e formativos, os espaços e os recursos necessários para realizar a ação pedagógica qualificada, valorização da atividade docente, com vistas à adoção de uma política permanente de estímulo à profissionalização, jornada única, formação continuada, melhoria da remuneração e garantia de condições dignas de trabalho.

\section{Notas}

1 Altera dispositivos da Lei no 6.019, de 3 de janeiro de 1974, que dispõe sobre o trabalho temporário nas empresas urbanas e dá outras providências; e dispõe sobre as relações de trabalho na empresa de prestação de serviços a terceiros.

2 Altera o Decreto-Lei n 5.452, de $1^{\circ}$ de maio de 1943 - Consolidação das Leis do Trabalho, e a Lei no 6.019, de 3 de janeiro de 1974, para dispor sobre eleições de representantes dos trabaIhadores no local de trabalho e sobre trabalho temporário, e dá outras providências.

3 Altera os arts. 37, 40, 109, 149, 167, 195, 201 e 203 da Constituição, para dispor sobre a seguridade social, estabelece regras de transição e dá outras providências.

\section{Referências}

ASSUNÇÃO, Alda Ávila; OLIVEIRA, Dalila Andrade. Condições de trabalho docente. In: OLIVEIRA, Dalila Andrade; DUARTE, Adriana Maria Cancella; VIEIRA, Lívia Maria Fraga. Dicionário: trabalho, profissão e condição docente. Belo Horizonte: UFMG/ Faculdade de Educação, 2010. CDROM.

ASSUNÇÃO, Alda Ávila; OLIVEIRA, Dalila Andrade. Intensificação do trabalho e saúde do professor. Educação e Sociedade, Campinas, v. 30, n. 107, p. 349-372, maio/ago. 2009. Disponível em: http://www.cedes.unicamp.br. 
BALL, Stephen J. Performatividade e fabricações na economia educacional: rumo a uma sociedade performativa. Educação e Realidade, v. 2, n. 32, p. 37-55, maio/ago. 2010.

BALL, Stephen. Performatividade, privatização e o pós-Estado do bem-estar. Educação e Sociedade, Campinas, v. 25, n. 89, p. 1105-1126, set./dez., 2004. Disponível em: http://www.cedes. unicamp.br.

BALL, Stephen. J. Profissionalismo, gerencialismo e performatividade. Cadernos de Pesquisa, São Paulo, v. 35, n.126, p. 539564, set./dez. 2005.

BALL, Stephen J. Sociologia das políticas educacionais e pesquisa crítico-social: uma revisão pessoal das políticas educacionais e da pesquisa em política educacional. In. BALL, Stephen J. MAINARDES, Jefferson (Org.). Políticas educacionais: questões e dilemas. São Paulo: Cortez, 2011, p. 21-53.

BRASIL. Constituição Federal (1988). Emenda constitucional n. ${ }^{\circ}$ 95, de 15 de dezembro de 2016. Altera o Ato das Disposições Constitucionais Transitórias, para instituir o Novo Regime Fiscal, e dá outras providências. Diário Oficial da União, Brasília: DF, 2016.

BRASIL. Lei $\mathbf{n}^{\circ} \mathbf{1 3 . 4 1 5}$, de 16 de fevereiro de 2017. Altera as Leis ns 9.394, de 20 de dezembro de 1996, e 11.494, de 20 de junho 2007, a Consolidação das Leis do Trabalho - CLT, aprovada pelo Decreto-Lei no 5.452, de 10 de maio de 1943, e o Decreto-Lei no 236 , de 28 de fevereiro de 1967; revoga a Lei no 11.161, de 5 de agosto de 2005; e institui a Política de Fomento à Implementação de Escolas de Ensino Médio em Tempo Integral. Diário Oficial da União, Brasília: DF, 2017.

BRASIL. Lei n 13.429, de 31 de março de 2017. Altera dispositivos da Lei no 6.019, de 3 de janeiro de 1974, que dispõe sobre o trabalho temporário nas empresas urbanas e dá outras providências; e dispõe sobre as relações de trabalho na empresa de prestação de serviços a terceiros. Diário Oficial da União, Brasília: DF, $2017 f$.

BRASIL. Ministério da Administração Federal e Reforma do Estado. Plano diretor da reforma do aparelho do Estado. Brasília, Imprensa Nacional, 1995. Disponível em: <http://www.bresserpereira.org.br/documents/mare/planodiretor/planodiretor. pdf> Acesso em 20 de abril de 2017.

BRASIL. Ministério da Educação. Lei de Diretrizes e Bases da Educação Nacional. Lei no 9.394 de 20 de dezembro de 1996, Brasília, DF, 20 dez. 1996.

BRASIL. Projeto de Lei $\mathbf{n}^{\circ} \mathbf{6 . 7 8 7}$, de 2016. Altera o Decreto-Lei n 5.452, de $1^{\circ}$ de maio de 1943 - Consolidação das Leis do Trabalho, e a Lei n 6.019, de 3 de janeiro de 1974, para dispor sobre eleições de representantes dos trabalhadores no local de trabalho e sobre trabalho temporário, e dá outras providências. Diário do Congresso Nacional. Disponível em: <http://www2. camara.leg.br/deputados/discursos-e-notas-taquigraficas/ discursos-em-destaque/projeto-de-lei-no-6787-2016-reforma-trabalhista/projeto-de-lei-no-6787-2016-reforma-trabalhista>. Acesso em: 25 de maio de 2017.

DUARTE, Alexandre William Barbosa; OLIVEIRA, Dalila Andrade. Valorização profissional docente nos sistemas de ensino de Minas Gerais e Pernambuco. Práxis Educacional, Vitória da Conquista, v. 10, n. 17, p. 67-97, jul./dez. 2014. Disponível em: <http://periodicos.uesb.br/index.php/praxis/article/viewFile/4527/4328> Acesso em: 02 de junho de 2017.

MELO, Claudiana Maria Nogueira de. Programas de Formação de Professores Alfabetizadores de Crianças: análise dos aspectos Políticos e Pedagógicos. 2015. 165 f. Tese (Doutorado) - Programa de Pós-Graduação em Educação Brasileira, Universidade Federal do Ceará, Fortaleza, 2015.

NUNES, Claudio Pinto; OLIVEIRA, Dalila Andrade. Trabalho, carreira, desenvolvimento docente e mudança na prática educativa. Educação e Pesquisa, São Paulo. v. 43, n.1, p.65-80, jan./ mar., 2017.

SAMPAIO, Maria das Mercês Ferreira; MARIN, Alda Junqueira. Precarização do trabalho docente e seus efeitos sobre as práticas curriculares. Educação e Sociedade, Campinas, vol. 25, n. 89, p. 1203-1225, Set./Dez. 2004. Disponível em: http://www. cedes.unicamp.br

SCHEIBE, Leda. Valorização e formação dos professores para a educação básica: Questões desafiadoras para um novo Plano Nacional de Educação. Educação e Sociedade, Campinas, v. 31, n. 112, p. 981-1000, jul.-set. 2010. Disponível em: http:// www.cedes.unicamp.br.

Recebido em 17 de maio de 2017.

Aceito em 22 de julho de 2017. 